\title{
Euthanasia, Ethics and Theology: A Dutch Perspective
}

\author{
THeO A. BOER*
}

In 2002, the Netherlands was the first country in the world to legalize euthanasia and physician-assisted suicide. What does the Dutch euthanasia practice look like? What are the insights gained from twelve years of experience in regulating and reviewing euthanasia cases? In this article, some observations about the practice and the backgrounds of euthanasia are made from the perspective of a theological ethicist.

Keywords: euthanasia, physician-assisted suicide, review committees, Netherlands, ethics, theology

\section{Introduction}

The Netherlands is one of the few countries in which euthanasia and physician-assisted suicide (PAS) have been legalized. ${ }^{1}$ Legalization was preceded by a process of deliberation and a practice of tolerance. In the mid-1980s the Royal Dutch Medical Association (RDMA) and the Public Prosecutor agreed that if a set of strict conditions were to be met, a doctor performing euthanasia would not be persecuted. Euthanasia was defined as "active life termination by a doctor, at the patient's request". ${ }^{2}$ The termination of a person's life without his or her request is not referred to as 'euthanasia' and does not fall under the criteria.

The criteria include that there must be a voluntary and informed request, the suffering is experienced as unbearable, there is no prospect of improvement, there are no acceptable alternatives, a second doctor has been consulted, and the euthanasia must meet state-of-the-art medical standards. Every case of euthanasia had to be reported to the Public Prosecutor who would assess whether the criteria had been met. From 1998 on, five Regional Review Committees, consisting of a lawyer, a doctor, and an ethicist took over the Public Prosecutor's task. Like the Public Prosecutor, they would assess a

\footnotetext{
* Theo A. Boer, Associate Professor of Ethics, Protestant Theological University, Groningen, the Netherlands, Prof. dr. G.A. Lindeboom Institute of Health Care Ethics, Theological University Kampen. Adress: Broederweg 15, 8261 GS Kampen; e-mail: taboer@pthu.nl.

1 In this article, wherever 'euthanasia' is used, please read "euthanasia and physician-assisted suicide".

2 Staatscommissie Euthanasie, Rapport van de Staatscommissie Euthanasie: Advies, Den Haag, Staatsuitgeverij 1985.
} 
euthanasia case in hindsight. From January 1, 2002 this practice was legally formalized and slightly changed: whereas previously every case was sent to the Prosecutor for a final assessment, from then on only cases that did not meet the criteria were sent to the Prosecutor. When a committee judges a case to be in compliance with the due care criteria, a verdict is final. Roughly one out of 600 cases does not meet the criteria. In the great majority of these cases, the problem is of a procedural nature: the medication did not meet the current criteria or there was no proper consultation by a second physician.

In religious circles, the reaction was mixed. Orthodox protestant theologians, such as Willem Velema and Jochem Douma, were fiercely opposed. The renowned liberal theologians Harry Kuitert and Heleen Dupuis played a major role in promoting euthanasia in both a Christian and a secular audience. Whereas the Roman Catholic Church was consistently opposed, the Protestant Church in the Netherlands took a more nuanced stand and declared in 1986 that euthanasia can be justified in exceptional cases. ${ }^{3} \mathrm{~A}$ decade later the two denominations issued a declaration against the impending euthanasia law of 2002.4 "Exceptions can be justified, but they do not need a law," was the logic behind the apparent 'turn to the right' of the Protestant Church.

According to the euthanasia law, it continues to be unlawful to take another person's life, yet under the aforementioned criteria a doctor enjoys immunity from prosecution. The review committees function as proof of the general principle that euthanasia is not, and should not become, normal medical practice. Since 2005, I have served as the ethicist of one of the committees. In this article I want to share some of the observations, based on my own analysis of 3,500 reports, or representative samples thereof, submitted to one of the five review committees in the years 2005-2014. ${ }^{5}$ The Netherlands is, in a certain sense, a laboratory from which other countries may draw lessons when considering the option of legalizing euthanasia. From the onset of the Dutch euthanasia practice, the vast majority of euthanasia cases take place in a context of terminal cancer, days or weeks before a natural death was expected. These cases are also known as 'traditional euthanasia cases.' A 2007 survey showed an unexpected decrease of $30 \%$ or so in the numbers of euthanasia. ${ }^{6}$

3 Gereformeerde Kerken in Nederland, and Nederlandse Hervormde Kerk, Euthanasie en Pastoraat, Den Haag 1988.

4 Frits de Lange, Jan Jans (eds.), De dood in het geding, Kampen 2000.

5 The thoughts expressed in this article are of a personal nature and do not represent the official view of the committees. Quotations and other information from the reports have been changed so as to protect the privacy of those involved.

6 Gerrit van der Wal et al., Evaluatie van de Wet toetsing levensbeëindiging op verzoek en hulp bij zelfdoding: praktijk, melding en toetsing, Utrecht 2007. 
Given the simultaneous increase in the number of palliative sedation cases, the conclusion was reached that doctors preferred palliative sedation above euthanasia. Palliative sedation is emotionally less burdensome and does not involve a review procedure. Since then, however, the number of reported case has unexpectedly and steadily gone up. The number of reported cases has increased from 1,923 in 2006, to 2,331 in 2008 and 3,136 in 2010 to 4,188 in $2012,{ }^{7}$ with a tendency toward a further increase after that year. It should be noted that the overall mortality figures have remained stable during that same period.

Most physicians make use of a standard reporting document made up of questions about the patient's medical condition, the reasons why the suffering is experienced as unbearable, and data regarding the patient's request: Is he competent? Was there outside pressure? When did the patient bring up the issue for the first time? The reports include a report by a second doctor who has visited the patient and gives his own assessment with regard to the due care criteria. These doctors are called SCEN-doctors (Support and Consultation Euthanasia in the Netherlands).

\section{Euthanasia and Autonomy}

\section{Introduction}

The Dutch euthanasia law only permits euthanasia if the patient makes a request which is informed, lasting, and voluntary. Only seldom does a request come totally unexpected; many requests take a typical 'three-stage' form. Many people express a preference for euthanasia many years or even decades prior to their actual death. This preference may take the form of a signed advance directive (and/or membership of the Dutch Right to Die-Society, NVVE) or the form of oral expressions. "Since we met twenty years ago", a doctor writes, "this patient has talked about having euthanasia in the case of a serious disease." "Since she can remember," a physician writes about a woman in her early forties, "she has been preoccupied with finding the right way to die." Such long-term expressions of one's personal morality help a physician to assess whether or not a euthanasia request matches a patient's worldview and character. Secondly, patients often bring up a 'conditional desire' to have euthanasia after a fatal diagnosis is obtained. Thirdly, and more than anything else, there needs to be an actual and immediate request at the end of a period of suffering, which normally includes a preference for a method and an approximate date. A patient's earlier preferences (oral or written) never

\footnotetext{
Regional euthanasia review committees, Annual Report 2012, The Hague 2013.
} 
suffice for euthanasia if there is not, in addition, an actual request. The time between this actual request and the euthanasia may be weeks, days, or even hours. The shorter this period, the more important become expressions of a patient's prior preferences.

A patient's preference may take different forms and have different degrees of intensity. In some cases a doctor refers to pressure on the side of the patient. This may be the doctor's way to preclude doubts regarding the voluntary character of the request. Sometimes the pressure from the side of the patient and his relatives can be so strong that the question arises of how free the doctor was to make his own assessment about the severity of the suffering and the absence of alternatives. In about one out of thirty cases, a patient lends weight to a request by mentioning the possibility of ending his own life or by mentioning earlier plans to do so. "He tells me that if I do not help him, he will hang himself", a doctor writes, and another doctor: "This man is demanding. He has attempted to commit suicide twice and a third attempt would have huge repercussions for the whole ward." Sometimes there is cynicism between the lines. "Her wish has always been everyone's command," a doctor writes about a former high school director. Another physician observes almost aloof: "If things don't go the way Mother wants them to go, this stirs Mother's irritation." Doctors normally refer to such pressure as proof of the severity of the suffering and of the firmness of a request.

\section{Loss of Autonomy as a Reason in Itself}

For about $60 \%$ of the patients the irreversible loss of autonomy itself, which is typical of many situations of terminal cancer, is a reason underlying a euthanasia wish: being bound to home, having become entirely care-dependent and/or bedridden, not being able to go to the bathroom or to plump up one's own pillow. "Being totally dependent on others does not match the person he used to be," a physician writes, "He was co-director of a big company for years and was used to having things go his way. Every request for help was an agony for him." For many patients, dependence upon others for one's daily needs runs counter to their idea of a good life. "I am no longer a full human being," a man explains, "my friends only visit me out of pity." "An object of care," a lady complains, "is all that is left of me." Often the contrast between better days long gone and the present situation constitutes an important part of the suffering: a sportswoman who is bedridden, a company director who has become care-dependent, a motorcyclist who feels stuck within the four walls of his room, a once very talkative man who can no longer speak as a consequence of laryngeal cancer, a policeman who always sought to assist others who now has to beg for help, a woman with a passion for hiking now 
bound to a wheelchair. Relatively frequently - in about one out of fifty cases patients refer to a previous career in care giving. "She has been a nurse all her life," writes a physician, "but having others take care of her is the last thing she would accept." "An important part of her self-esteem consisted in taking care of others. Now that she can no longer care, her life lacks meaning." In most cases the loss of independence comes together with other forms of suffering but for some, the mere fact of being dependent, rather than the medical inconveniences coming with it, constitutes the suffering. We will come back to this 'shift of paradigm' in section 6 .

\section{Suffering}

Many euthanasia requests are made by patients whose lives are described primarily, if not exclusively, in terms of suffering. In the great majority of cases the physical discomfort leading to a euthanasia request consists of pain, nausea, dependence on others, dyspnoea, extreme fatigue, anxiety, loss of body functions, meaninglessness, and loneliness. Some reports are especially compelling. "Her sister vividly explains her predicament. There is nothing left she can do; she can't even wipe away the tears from her own eyes." A doctor writes about a patient with metastases in the bones. "Last week he broke two ribs when he was assisted in going to the bathroom. The next day he sneezed and broke another rib. Now he won't let anyone touch him, not even his own wife." The report of a woman with facial cancer who has small children is heartbreaking. "She wants euthanasia before her children start avoiding her and no longer show affection to her." For this woman the help she wants comes too late. A week before the euthanasia her six-year-old daughter stops exchanging signs of affection and avoids visiting her own mom. No wonder that some patients show enormous relief when they hear that their request will be granted. A man describes the appointed day of euthanasia as a "day of celebration." "When I tell her that I will fulfil her request," a doctor writes, "she becomes very emotional: a mix of laughing and crying, she claps her hands and starts hyperventilating from emotions." "When I tell her that the criteria have been met," a consulting doctor writes, "she insists on hugging me." The doctor is functioning here as a priest: holding the keys to a good death.

In some cases reference is made to positive side effects of waiting: "Patient wanted to have euthanasia months ago, but is happy to have waited some time. This difficult period has brought the family closer together." "Over the years she has learned to accept her increasing dependence. Some of her friends wash and bathe her, and she is comfortable with it." One doctor writes: "Pati- 
ent was a member of the Right to Die Society from its very beginning. Three months ago she insisted on having euthanasia. In hindsight she is happy I didn't satisfy her request. She has had many meaningful experiences since." "Patient was a construction worker for most of his life. During the two years of his sickness he finally learned to talk. He and his wife and kids have become a lot closer since." Amidst a process of physical withering the terminal phase thus provides opportunities for flourishing as well.

\section{Euthanasia and Quality of Care}

About one out of ten reports contains a reference to the quality of care. In a good deal of these cases there is gratitude on the side of the patient and his relatives for the efforts made by the caregivers. But there are also reports of insufficient care. One category of patients is the one of those who refuse to accept care, or for whom the option of a nursing home is unacceptable. "Palliative care could be better," a doctor writes, "but the patient rejects the alternatives. Euthanasia is all she wants." "This proud lady rejects being admitted to a nursing home. For her this equals unbearable suffering." "Tinkering with embroideries in some room, singing songs to keep up our spirits, I don't want all that," another lady is quoted, and an elderly man: "My bare bottom washed by a young girl, never!" "Patient finds the idea of someone else taking care of her horrifying." "On my question what makes her suffering unbearable," a physician writes, "she replies that it is the having to ask others for help. "Asking, asking, asking, I can't and I won't!»" For another man, a former faculty dean, the patronizing attitude of some of the staff is an essential reason for his euthanasia request.

Some people live in total social isolation. They do not know how to get access to care and are too tired or disillusioned to find out. "Patient is lonely, so lonely," a consulting doctor observes almost dryly. A doctor writes about a fifty-year old man who is handicapped after a motorcycle accident: "He deserves better care than he gets, but refuses. Getting bathed and dressed takes hours. The severity of his suffering is related to a total absence of social interactions." Some doctors describe patients who refuse better care as "antisocial" but nevertheless - albeit hesitantly - grant the patient's request.

Some suffering may be caused by too much treatment. The slightest perspective of healing is seized with both hands, but when all treatment has turned out to be futile, some patients are regretful. A doctor writes: "All in all patient received chemotherapy three times. There was no effect whatsoever, except that it ruined what was left of his wellbeing." Even reports without explicit allusions to the burdens of too much treatment impress the reader by 
references to an excess of invasive treatment. "I wonder whether all that treatment had much effect," a patient confides to his doctor, "but I have to blame myself. I consented." The question thus arises whether some of the suffering may have been aggravated by medical treatment. If that were the case, would it not have been better to resort to palliative care? But then, of course, others have survived cancer exactly thanks to invasive treatment. ${ }^{8}$

Unfortunately, some physicians contribute in their own manner to the patient's anxiety instead of providing reassurance. "His oncologist had told him that the rest of his life would be nothing but pain, pain, pain," a doctor writes. A colleague writes: "His pulmonologist sent him home with the warning that there is a real chance of suffocation." "Patient lives at home and a home health nurse visits him twice a day. Since he is incontinent, he sometimes lies in his own feces for a long time." "Patient hardly gets any help," another doctor writes, "and when he does, it is always someone different. In two weeks time he has seen twenty new faces."

Let me introduce Mrs. Hansen, 69 years old, an artistically gifted woman and a trained physiotherapist. Five years before her death she became addicted to the prescription painkillers of her late husband. Through a vicious circle she developed a kidney and a liver insufficiency. At the moment of her first euthanasia request, three years later, she was addicted not only to painkillers but also to sedatives, sleeping pills, and a number of other medications. At first her physician refused, but he changed his mind in the course of the years. "I have tried to talk her into a detoxification program," he writes, "but she quit with no success. In addition, she has a lot of social issues. She lost contact with her two sons and her only daughter visits her once a week and brings her some groceries." In this case there was one ray of hope: "Patient submitted an application to a nursing home two years ago and was looking forward to move there. Unfortunately, her application got lost and she will have to wait for another couple of years. This is unacceptable to her." Instead of demanding access to a nursing home this doctor then consents to performing euthanasia three weeks later. The case was judged to be adequate by the committee, but the questions remain. Like some of his colleagues, the physician seems to have entered an ever narrowing alley with no possible return. The combination of heavy involvement of the physician with a claiming patient in utter despair, a patient who wants euthanasia and refuses the alternatives, leaves a physician almost no choice. At some point in time, the doctor agrees that euthanasia

8 In the Netherlands, there is an increasing debate on problems regarding too much treatment. See, Theo Boer et al., Over (-) behandelen: Ethiek van de zorg voor kwetsbare ouderen, Amsterdam, 2013. 
is in fact the right thing to do. Although for many a physician it feels like a trap, the decision may also come as a relief: at last, no longer the concern for a patient in a state of utter despair. In other cases, the apparent absence of any attempt to find proper care may have been motivated by the short life expectancy of the patient, but not here. So why not make more attempts to arrange the best of care?

However, would the care in a hospital, nursing home, or hospice be that much better? The bad reputation of nursing homes, which is one of the reasons for qualifying a future transfer into such an institution as unbearable suffering, at least in part goes back to real problems: shortage of staff, insufficient hygiene, lack of privacy, and a socially undertrained staff. One reporting physician can hardly suppress his own evaluation of life in a nursing home: "I can sympathize with her request," he writes, "patient is totally care dependent and gets little personal attention." A patient in a hospital indicates that one of the motives for his euthanasia request is the fact that he never sleeps through the night. "Staying in a four-bed room, I am constantly being awakened by noises." "The institution he is in has a serious shortage of staff," another doctor writes, "Apart from the pain and the distress, he tells me he has lain in his own excrements a couple of times now, and he does not want that to happen again," and another, "The severe suffering of this man is intensified by the impersonal setting of his care institution." These case reports were all approved by the committee. After all, patients did suffer unbearably. Review committees are supposed to work within the framework of an existing health care system - not redesign it. Demographic developments in Western countries hardly provide much hope that the pressure on the already overstrained health care systems will decrease. The reports of these patients are heartbreaking and justify a public and political discussion which goes beyond traditional "pro" and "contra euthanasia" positions. Relatively late in comparison to other western countries, Dutch hospitals and physicians have seen the need to update the quality of palliative care. In the highly polarized Dutch euthanasia discussion in the 1990s references to inferior quality of care were seen as crypto-arguments against euthanasia and were met with suspicion. Those times are over. In a study published in 2009, Els Borst, under whose ministership the euthanasia law was accepted by the parliament, commented that euthanasia has come too early in the Netherlands: "We did it in the wrong order. [W] gave in to the political and societal pressure for euthanasia [before we had properly arranged palliative care]".

\footnotetext{
9 Anne-Mei The, Verlossers naast God: dokters en euthanasie in Nederland, Amsterdam 2009, p. 206.
} 


\section{New developments}

Although the vast majority of euthanasia cases still take place in the context of terminal cancer, we see some significant changes in the public discussion in recent years (roughly 2009-2013). Apart from the sharp rise of the numbers, three major changes seem now to occur.

\section{No longer terminal cancer}

Whereas it is plausible to assume that the 2002 euthanasia law was designed for situations of unbearable suffering in the case of a terminal disease, a new category of patients are those with suffering from other causes. As a 92-year-old lady describes: "I've wanted to die for years. Why must I have a serious disease before I may ask to be euthanized?" Her primary problem is not her health, but problems connected to her age. Increasingly cases like these constitute an important challenge to doctors in the Netherlands. As a physician observes, "[ $\mathrm{t}]$ he pain and the nausea are under control, but the real problem is that we haven't succeeded in finding a meaningful activity during his last weeks. He bluntly refuses every suggestion we make." "She rejected home care. She doesn't tolerate the hands of strangers to her body." "Patient has a tan and gives a vital impression. What really causes her suffering is that she can no longer make an essential contribution to the lives of others." "It's like floating in space," another patient describes his suffering, "there is no goal, no fixed points, just uncertainty and lack of meaning." "I am bored all day," a 70-year-old man complains, "The only thing I notice are cars parking in and out." About another patient a physician remarks emphatically: "All this respectable and once active lady can do is sit at the window and chase away the crows with her cane." Important to notice is a shift here: previously, a patient that expressed these concerns also suffered from a terminal disease. And that still goes for the great majority of patients requesting euthanasia. But in an increasing number of cases, an important part of the suffering is existential.

Sometimes a patient's euthanasia wish is hard to feel sympathy for. "The patient vividly tells me about the 'surplus value' of euthanasia. He had a fantastic life, and the way he dies should not spoil this". ${ }^{10}$ "Patient is known to be a true bon vivant. Being bed-ridden is not compatible with his conception of a good life." "I would prefer euthanasia as soon as possible," an elderly man says, "my grandson will start a bachelor program in physiotherapy next week and his father intends to run the New York marathon on Saturday". Remarks

10 See: Arend van der Meulen, "Dansend het leven uit"(Dancing out of Life) in: Dagblad van het Noorden, Febr. 1, 2014. 
like these sometimes raise doubts whether the suffering can be classified as unbearable. In the past five years, I remember only one case being sent to the Board of Procurators General on the basis of the argument that the suffering was not unbearable. Part of the explanation stems from the fact that a committee cannot possibly check the severity of a patient's suffering. It merely assesses whether the two physicians involved, did.

According to the highest court in the Netherlands, the euthanasia law does not require the presence of a terminal disease. ${ }^{11}$ In the Brongersma case of 2002, the High Court ruled that the suffering needs to be connected to a medically classifiable disease. This does not need to be terminal: it can also involve an illness that is chronic and not life threatening. The verdict ruled out euthanasia merely on the basis of an autonomous choice, while opening up a category of new cases. Examples are patients suffering from a combination of age-related diseases: macular degeneration (causing blindness), incontinence, arthritis, etc., in addition to, e.g., loss of status and loneliness.

\section{Euthanasia, Dementia, and Psychiatry}

In the first years of the euthanasia law, there were few reports of euthanasia for patients with psychiatric illnesses. Of a total number of about 2,000 cases per year, only four had a psychiatric background. The existence of a psychiatric illness hinders a free assessment by the patient of his situation. Moreover, the facts that euthanasia could shorten a patient's life by decades, and that, technically, there is a chance that the suffering may ease in the future, played an important role in the hesitation of doctors to perform euthanasia, and of Review Committees to approve a case. After 2007, the number of cases reported on the basis of a psychiatric illness increased. Whereas Review Committees spokespersons insist that the 2002 euthanasia law does include psychiatric illnesses, discussions continue to be held about the conditions under which a doctor can be certain that the conditions are met. In 2013 and 2014, media discussions concentrated on patients whotheoretically - could have lived for decades and who suffered from specific conditions: a healthy woman in her early sixties whose main reason for requesting euthanasia was blindness ("I can no longer see my grandchildren"); a man in his early sixties who had managed to live with his psychological instability with the help of a job, but who was sent into early retirement; and a woman in her thirties whose suffering consisted of mysophobia (fear of stains). The discussions focus on the possibility of alternative treatments,

11 This is contrary to the situation in both Oregon and Switzerland, where a natural death must be expected within six months. 
on the patient's competence, and on the question of how long and how well a physician should know a patient.

Similar developments are seen in the field of dementia: prior to 2007 there was not a single report of dementia as a reason for euthanasia. It was not that the law would rule it out, but in practice there was the awareness that euthanasia in the context of psychiatry raises complex ethical and legal problems. In an early stage of the disease, a patient may be competent but the suffering may not be unbearable; however, in an advanced stage, as the suffering may have aggravated (albeit not necessarily so), the patient may have become incompetent. Since 2007, the Review Committees have seen reports of euthanasia in different stages of dementia. In most of those cases, euthanasia was performed in an early stage. The reasons for a request consisted of actual suffering, the prospect of suffering, and fear that at a later stage the patient may have lost his competence. In August, 2011, the first case of euthanasia in an advanced stage of dementia was approved. The patient, a 65-year-old woman, had always expressed a fear of losing her competence and dignity. By the time her life was terminated, she had lost most of her mental capacities. After the case was approved, the second-opinion doctor, a declared advocate of euthanasia in dementia, announced in a national paper that now euthanasia in cases of advanced dementia is possible. ${ }^{12}$ Most early reactions to the news were neutral to positive. Months later another newspaper published a more critical reconstruction of the case in which it claimed that the woman in the end had resisted the euthanasia. ${ }^{13}$ Physicians previously known for their support of euthanasia joined in and argued that euthanasia can only be performed on people who are still competent. ${ }^{14}$ Since then, the RDMA and the Review Committees have debated the question of whether an advance directive suffices in the case of an incompetent person. ${ }^{15}$ The unclear outcome of this debate may be one of the reasons why since 2012 only few cases of euthanasia on patients with advanced dementia are known.

\footnotetext{
12 Constance Ekkers-de Vries, "Voor het eerst in Nederland euthanasie op zwaar dementerende patiënte" in: De Volkskrant, Nov. 9, 2011.

13 Antoinette Reerink, "De vrouw die niet meer wist dat ze dood wilde" in: NCR Handelsblad, Febr. 4, 2012; Bert Keizer et al., "Geen euthanasie bij demente die zich bedenkt" in: NRC Handelsblad, Febr. 10, 2012.

14 Cornelie Mijnarends, Euthanasie bij dementie: een casestudy, 2012. Under tutorship of Prof. Theo Boer. Utrecht, Protestantse Theologische Universiteit, 20 ff.

15 The case, known as case No. 7 in the 2011 Annual Report and discussed there, is not included in the abridged English version of the Report: Regional euthanasia review committees, Annual Report 2011, The Hague, Ministry of Health, 2012. For the Dutch version see: Toetsingscommissies Euthanasie, Jaarverslag Regionale Toetsingscommissies Euthanasie 2011, Den Haag 2012.
} 


\section{End-of-Life Clinic}

In the beginning of 2012, an initiative was launched by the NVVE: the End of Life Clinic in The Hague. This clinic sends out mobile teams consisting of a doctor and nurse to visit patients in their homes or in an institution. The process starts with a patient contacting the clinic and filling out a form, on the basis of which it is decided if a patient is eligible for euthanasia. Due to a waiting list and shortage of staff, the period between the first contact and this decision may take weeks to months. On the basis of one or two visits, and after taking into consideration all available information, the mobile team then decides whether or not a euthanasia procedure will be started (called 'triage'). One or two additional visits may be made, and after an independent doctor has given his assessment, the euthanasia is performed. Since 2012, the Euthanasia Review Committees have seen close to two hundred euthanasia cases; after intense discussions all cases but one were considered to be in accordance with the due care criteria. Although the committees try to reach a consensus, unanimity is not required: a decision is final and will be respected by the dissenting member.

The End-o-Life Clinic, then, raises several moral concerns. First there is the short period in which a patient-doctor relationship has existed. In countries abroad, the Dutch practice has enjoyed much respect on the basis of the system of home-doctors. The same doctor who helped a family deliver a baby and manage a variety of health related problems, will likely be able to assess the seriousness of a patient's situation and the voluntary character of the request better than a doctor who just got to know a patient. A long-time relationship helps to prevent too hasty decisions. To be sure, even in regular euthanasia practice there are situations, e.g., being on leave, in which a doctor hands over a case to a colleague. Such transfers are exceptional and everything possible is done to ensure as much continuity as possible. In the case of the End of Life Clinic however, a short relationship is one of the trademarks of the clinic. ${ }^{16}$

Another issue in this context is that in most cases a patient's own physician (home physician, oncologist, physician, etc.) has refused to grant a request. Only in exceptional cases is this refusal motivated by a categorical rejection of euthanasia by the patient's own doctor. In most cases, the patient's own physician refuses euthanasia in this particular case: the suffering is not considered to be unbearable, the life expectancy is too long, measures can be taken to ease the suffering, the request is not well-informed or autonomous enough,

16 Professor Govert den Hartogh, former member of one of the committees, describes the End of Life Clinic as a form of "organized carelessness". Govert den Hartogh, "Levenseindekliniek binnen de grenzen van de wet?" in: Tijdschrift voor Gezondheidsrecht 35 (3/2011), p. 212-216. 
a patient is too demanding, etc. To be sure, the physicians associated with the End-of-Life Clinic (and their consultants) do make their own assessments about the due care criteria. But the fact that the patient's own doctor(s) and the doctor of the End-of Life-Clinic come to different conclusions deserves systematic attention.

A third problem connected to the End-of-Life Clinic is the fact that the physicians involved have only two options: euthanasia or nothing. Even if some of them are trained in providing alternative palliative options, they do not have the funding. In a more conventional setting, a doctor who refuses to perform euthanasia will still be the patient's doctor. But in the case of the End-of-Life Clinic, a refusal to perform euthanasia puts to an end the very relationship. This fact implies the risk of tunnel vision on the side of both the doctor and the patient and his relatives.

The Dutch euthanasia law does not include a long-term patient-doctor relationship in the criteria, nor does it require the availability of a wider array of palliative options. At the time of its origination, the early1990s, these contextual factors were beyond doubt, as the existence of mobile euthanasia teams could hardly be anticipated. In hindsight, the Lawgiver might have wanted to make more explicit reference to these criteria.

\section{Theological Notions}

\section{Introduction}

As previously stated, the Netherlands was the first to legalize euthanasia. Over the last decade, only Belgium and Luxemburg have followed this example. In Oregon, Washington (State), Vermont, and Switzerland assisted suicide is legal, but on the condition that a natural death is expected within months.

What are the reasons for this exceptional position? The Dutch-Reformed tradition of Protestantism, with its focus on individual responsibility both in explaining Scripture and in moral decision-making, may be one of them. Moreover, there is the Dutch history of liberalism and pluralism: as a seafaring nation, the Netherlands has historically been in contact with and host to people of different ideological and religious backgrounds. The Dutch position may also be explained by the absence of a Natural Law tradition. Leading Reformed theologians have stressed the corruption of reason and insisted on a close link between Scripture and morality. For religious and secularized debaters alike, the rejection of religious convictions was assumed to logically imply the rejection of a traditional morality. There have been media discussions in which Reformed Christians virtually prove their opponents right in abandoning a traditional morality and embracing a liberal one: once 
these opponents - tragically - have rejected the Bible as the basis for ethics, what else is there left?

More recently, there is a propensity among Dutch theologians to explain, if not rephrase, traditional Christian moral tenets in terms of what can be understood (if not accepted) by a non-religious audience. For this purpose, not only philosophical and Natural Law methods and insights, but also insights from practical theology prove to be valuable. The key question for theologians is: is it possible to be critical of euthanasia with the help of a generally accessible vocabulary?

A Review Committee assesses each euthanasia case in the light of three norms: the Law, state-of-the-art medical practice, and medical ethics. For me as an ethicist, my theological background provides heuristic tools for asking questions, formulating criticism, and finding answers. Christians have a tradition of reflecting on the good life and a good death, aware of the ancient wisdom that 'only that is well that ends well.' In the Early Church, a good death, eu-thanatos, was believed to be a death in peace with God. As such, it was not the end but the transition into a new life. What matters was, in the opening words of the compline prayer, "a perfect end."

As the conviction fades that "our present sufferings are not worth comparing with the glory that will be revealed in us" (Rom. 8. 18, NIV), the 'present sufferings' become harder to bear. As for many pious Christians for whom a good death stands at the end of a lifelong process of pious living, modern people see euthanasia as the result of a year-long process of preparing one's death. Modern lives can be seen as a pilgrimage towards a comfortable and manageable death, similar to Christian's journey to 'Celestial City' in John Bunyan's Pilgrim's Progress. And unlike the believer, the modern, autonomous person has to provide his own comfort. ${ }^{17}$

\section{Worlds Apart}

How, then, do we describe 'euthanasia'? We can roughly discern three kinds of descriptions. First, some speak of euthanasia in terms of its most plain sense: the direct, active, and direct killing of a person. In general, only opponents to euthanasia will use this vocabulary. (In the case of a strong rejection, some will include the term 'murder.') A frequent alternative is to speak in terms of going to sleep - a term that circumvents the directness and the finality of the act, alludes to the transition into a life hereafter ("falling asleep and waking up on the other side," as one patient puts it), and stresses the similarity to other acts

17 See: Leo Enthoven, "Mooie euthanasie als einde na een mooi leven" (a good euthanasia after a good life) in: Relevant (Quarterly of the NVVE) 39 (3/2013), p. 8-9. 
performed by a doctor during a lifetime. Thirdly, euthanasia is referred to in terms of a dignified death. It is this latter sense that I will focus on, given its key role in contemporary discussions about the legalization of euthanasia. ${ }^{18}$

In what sense, then, could euthanasia be said to be a dignified death? A first option is to tie it to the adequate relief of suffering. There is little doubt that pain, fear, dependence, incontinence, loneliness, and incompetence pose serious threats to a person's dignity. The 2002 euthanasia law (as well as laws in other countries), by stressing the criteria of unbearable suffering and the absence of palliative alternatives, reflects this paradigm. Euthanasia in this sense can be illustrated by the traditional ethics-class case of a truck driver who, after crashing into a concrete wall, is stuck and begs a bystander to shoot him before he is consumed by the flames. Such a killing is as exceptional as it is tragic, to be resorted to only when no alternatives are available. A patient's request is necessary but not sufficient. A doctor should be able to make his own observations about the nature and seriousness of the suffering.

More and more frequently, dignity becomes tied to the concept of personal autonomy. Those who make this turn see a person's informed wish not only as a necessary but also as a sufficient condition for euthanasia. In 2006, the NVVE adopted a name change. Their primary concept is no longer euthanasia but a 'voluntary death'. This then, renders the ' $E$ ' in its name obsolete. No doubt, alleviation of suffering continues to play a role in a euthanasia request: someone who is perfectly happy and healthy will hardly be prone to issue a request. But a person may have more reasons than suffering, e.g., that a good death is a timely death, that euthanasia is a manageable death, that euthanasia matches his aesthetic standards, that the finances necessary for caregiving cannot be obtained, or a future loss of one's mental sharpness. In this option a death is dignified if it is the result of an autonomous choice to write the last chapter in one's own biography. The task of a physician is not to check the seriousness of the suffering but the seriousness of the request.

The two options often go mixed, but are worlds apart. The first view - euthanasia as a last resort in the case of unbearable suffering (at a patient's request) - lies at the basis of the Dutch euthanasia law. It is this view which also explains the 'no, unless' viewpoint of the Protestant Church in the Neth-

\footnotetext{
18 The Dutch Right to Die Society uses euthanasia and "dignified death" almost synonymously. The proximity of the concepts of euthanasia and dignity is also reflected in the fact that the US organization which promotes physician-assisted suicide calls itself the "Death with Dignity National Center". Likewise, the Twitter account of the Dutch Right to Die Society NVVE is called @waardigsterven. All this, in a sense, includes claiming the concept of dignity for a particular way of dying.
} 
erlands, referred to above. Central is the conviction that human life is not at our disposal, not even to the person herself. In this view, the duty to protect human life can be overruled only in the case of an emergency. The second view - focusing on autonomy - takes a very different angle. It should be noted, however, that a secular and liberal anthropology does not necessarily include a libertarian view of euthanasia. ${ }^{19}$ Even philosophers such as Kant ("suicide is wrong because it destroys one's autonomy"), John Stuart Mill ("suicide equals selling oneself as a slave"), and Camus ("those who decide to live are the real heroes") stress the importance of protecting one's own life. The autonomy, which characterizes us as moral beings, should be used to make possible our future autonomy, not to destroy it. As a theologian, I agree with the Reformers that our lives are begotten, not made, and that our existence as persons is a gift from God to be protected and cherished. To a certain extent this confession can be shared by others and stated in non-theological terms. No one asked our permission to cause our existence any more than we are able to exert influence on our ethnicity, nationality, gender, hair colour, or character. I am convinced that the assumption of a right to consent to our existence, including a right to end it at our discretion, is mistaken. Life as such commands us to respect it.

These insights need to be reflected in our legal system. A society has a duty to protect every individual human life, not only from infringements by others, but also from ourselves. Each decision to terminate one's life should be left for what it is: an uncommon and dramatic decision, a rare exception to the rule. Never should the possibility of euthanasia come to mark the end of our duty to protect and advance life. Euthanasia becoming a right (and, $a$ fortiori, a right based on individual autonomy alone) raises many concerns. Family pressure is one of them, financial pressure another. European societies have an increasing problem in financing and organizing care for its elderly. In some countries, like Germany, children have a legal duty to contribute financially to the care of their parents. Other countries - like the Netherlands - are likely to follow. This includes the danger that elderly people will feel an obligation to end their lives when the care becomes the most costly. Most fundamentally, a right to have one's life terminated - "no questions asked" collides with the duty to do what we can to protect individual human life, a duty underlying all accounts of human rights.

\footnotetext{
19 However, even religious voices are heard in favor of it, as the words of the French theologian Jacques Pohier illustrate: "God not only gave humans partial liberty [...] It is almost a blasphemy to assume that God gave us life without us being able to freely dispose over it, for better or for worse, according to our own judgment," in: Marc Horwitz, "L'euthanasie en débat" in: Actualité Religieuse dans le monde 119 (2/1994), p. 26.
} 
The urgent question begging to be answered in the coming years is this: once a euthanasia law has been passed, how likely is a paradigm shift to happen from 'euthanasia as a last resort in unbearable suffering' to 'euthanasia as a right, based on autonomy'? On the basis of the Dutch experience, there are indications that such a shift is not unlikely to occur. ${ }^{20}$ Other countries that consider a legalization of euthanasia may want to consider this in the process of choosing the exact wordings and criteria contained in a new law.

20 In 2007, I wrote an article in the Journal of Religious Ethics in which I contended that the Dutch practice proves that there needs not to be a slippery slope once euthanasia has become legal. Seven years later, I may have to nuance this conclusion. Theo A. Boer, "Recurring Themes in the Debate about Euthanasia and Assisted Suicide" in: Journal of Religious Ethics 35 (3/2007), p. 529-555. 